\title{
Oral and peri-oral signs and symptoms of herbal dentifrices in patients in two oral medicine clinics in Lagos-A preliminary study
}

\author{
Abiodun Arinola Wright ${ }^{*}$, Gbemisola Adewunmi Agbelusi², Adeyinka Folashade Dayo ${ }^{3}$, \\ Onomoare Juliana Olunuga ${ }^{1}$ \\ ${ }^{1}$ Dental Department, Randle General Hospital, Lagos, Nigeria \\ ${ }^{2}$ Department of Preventive Dentistry, Faculty of Dental Sciences, College of Medicine, University of Lagos, Lagos, Nigeria \\ ${ }^{3}$ Department of Preventive Dentistry, Lagos University Teaching Hospital Idiaraba, Lagos, Nigeria \\ Email: "bdnwright@yahoo.com
}

Received 4 November 2011; revised 26 December 2011; accepted 7 January 2012

\section{ABSTRACT}

Background: Herbal dentifrices appear to have become an attractive alternative for some consumers and its use has gained appreciable acceptance in Nigeria. This could be partly due to the perception that herbal toothpastes like other herbal products are "natural", devoid of chemicals and therefore superior to regular toothpastes. Aggressive advertisement of the products may also contribute to this new trend. Mucosal symptoms such as glossitis and intolerance to spicy foods seen in patients attending the oral diagnosis clinic are usually associated with anaemia and nutritional deficiency states. The disturbing trend of an increasing number of patients presenting with such oral mucosal symptoms associated with the use of herbal dentifrices prompted this study. This trend was observed in two isolated oral medicine clinics. Objective: To sensitize oral health, allied professionals and consumers on the possible adverse effects of regular use of some herbal dentifrices sold in Nigeria. Materials and Methods: Routine patients of two oral medicine clinics in Lagos, namely the Randle General Hospital and the Lagos University Teaching Hospital who complained of some adverse mucosal signs and symptoms following the regular use of two identified herbal toothpastes made up the study population. The study was conducted between April 2010-April 2011. A detailed history and examination was carried out on these patients and clinical photographs of oral signs observed was taken in consenting patients. Data analysis was done using the Epi-info 6 software. $P$ values $\leq 0.05$ was considered statistically significant and data was presented in table format. Results: A

${ }^{*}$ Corresponding author. total of 45 patients, $9(20 \%)$ males and $36(80 \%)$ females were seen. The age range of patients was 14 78 years; mean age $45.5 \pm 14.9$ years. The duration of use of herbal dentifrices ranged from 2 weeks - 84 months (mean $24 \pm 11.5$ months). Oral signs and symptoms seen include, burning mouth and peppery sensation, mucosal erythema, lichenoid reaction, xerostomia, loss of taste sensation, angio-oedema and oral and peri-oral pigmentation. In many patients, resolution of symptoms was progressive within 2 weeks of withdrawal of the herbal toothpaste and its replacement with a conventional fluoride toothpaste. Most of the patients however required further treatment. A statistically significant association was found between the use of the identified herbal dentifrices and the following mucosal signs and symptoms namely, burning mouth and peppery sensation, loss of taste sensation, soreness, erythema and lichenoid straie ( $p$ value $\leq \mathbf{0 . 0 5}$ ). There was no statistically significant association between the use of herbal toothpaste and mucosal signs and symptoms of xerostomia, angular cheilitis, mucosal itching, angio-oedema and numbness ( $p$ value $>\mathbf{0 . 0 . 5}$ ) Conclusion: The regular use of the herbal dentifrices identified in this study can result in oral signs and symptoms affecting taste, nutrition, aesthetics and general oral physiology in some consumers. These findings suggest that further long term clinical trials need to be conducted on the herbal dentifrices to identify the noxious agents causing these symptoms. The formulation and use of these dentifrices need to be standardized and regulated. There is also a need to formulate a treatment protocol for these patients.

Keywords: Herbal Dentifrices; Oral Mucosal Signs and Symptoms; Burning Mouth 


\section{INTRODUCTION}

The use of herbal remedies have assumed a global dimension culminating in its being used in the treatment of various ailments in both developed as well as developing countries. This alternative form of therapy appears to be the latest fad, as a number of herbal products are readily available to consumers. Teas, soaps, facial products, colon cleansers, as well as mouth washes and dentifrices are a few of these products.

It is reported that herbal medicines are the mainstay of health care for a large proportion of the population in underdeveloped countries due to a combination of nonavailability of modern medical care, ignorance and poverty $[1,2]$. Over three-quarters of the population in subSaharan Africa reportedly depend on traditional medicine for primary health care, [3-5]. More than $60 \%$ of the Chinese use herbal therapy [6] and a significant part of the rural population in the Indian subcontinent rely on indigenous medical systems that use herbs, ash and heavy metals [7].

The use of herbal medicine has also reportedly increased in developed countries [8]. An estimated onethird to one-half of all Americans practice some form of alternative medicine including use of natural or herbal health care products [9-12] Several authors opined that the use of these products, including dentifrices, has increased significantly in the last decade [13-16].

A number of articles have been written on the efficacy or otherwise of herbal dentifrices. Some reports indicate that the lack of a consensus among dental professionals on the subject matter has made it difficult for dentists to provide information on the product safety and efficacy [17].

Dentists in particular have been advised on the need to be cautious and well informed on the inherent dangers associated with herbal ingredients in dentifrices that lack specific and defined requirements and regulations [1721].

A dearth of scientific studies on natural and herbal products in peer reviewed dental literature has also been cited as posing a conundrum for health care professionals in dealing with these products. In addition, few research efforts have been directed toward addressing the potency or quality of herbal ingredients used in these dental products [17]. Reports have also indicated that since only a limited number of in vivo studies on herbal dentifrices have been published, it has not been determined whether they are superior, equivalent or substandard to conventional dentifrices in reducing plaque [18-20].

Herbal toothpastes are readily available to consumers in the open market in Lagos, Nigeria. Marketers of some of the conventional fluoride toothpaste brands in Nigeria have also included herbal variants in their product range.
It is expected that this study will educate and sensitize individuals, and prompt appropriate agencies and institutions on the need to collaborate in evolving the development of a template for research, standardization and regulation of non-conventional toothpastes.

\section{MATERIALS AND METHODS}

The study which spanned over 12 months was conducted in two separate oral medicine clinics in Lagos; the Randle General Hospital and the Lagos University Teaching Hospital (LUTH) between April 2010 and April 2011. The study population comprised patients seen in the oral medicine clinics with oral mucosal signs and symptoms following daily use of two identified herbal toothpastes.

The identified toothpastes are referred to as Toothpaste A and Toothpaste B for the purpose of this study. The active ingredients in Toothpaste $\mathrm{A}$ as indicated on the product package include rosemary, sage, myrrh, eucalyptus, chamomile and other natural oils.

Sodium fluoride, eucalyptus, peppermint, thyme, and aloe vera leaf extract are the active ingredients on the product package in Toothpaste B.

A comprehensive history of the signs and symptoms was obtained from the patients. History included presenting complaints, duration of symptoms, type of herbal dentifrice and the duration of use of herbal product. Additional information on whether or not the use of the toothpaste was based on recommendation by a dental professional was also obtained.

Intra and extra oral examination of the patients was carried out and findings were documented in patient's clinical notes. Clinical photographs of oral lesions were taken in consenting patients. Patients were given a 2week recall appointment after being advised to discontinue the use of herbal dentifrice and replace with a conventional fluoride toothpaste of their choice.

Some patients required additional investigations and further treatment. Data analysis was done using the Epi-info 6 software with consultation of a statistician and presented in table format. Significance in association was inferred with $\mathrm{p}$ values $\leq 0.5$.

No control group was included in this study owing to the incidental nature of the findings during consultation as well as the preliminary nature of the study.

\section{RESULTS}

Observation from the study gave varied clinical signs and symptoms following regular use of the two identified herbal toothpastes. Forty-five patients had symptoms following consistent use of herbal toothpaste over a period of time. A total of 45 patients, $9(20 \%)$ males and 36 $(80 \%)$ females were seen. The male: female ratio was 1:4. The age range of patients was $14-78$ years, mean age 
$45.5 \pm 14.9$ years. Age and sex distribution in the patients is seen in Table $\mathbf{1}$.

The duration of use of herbal dentifrices ranged from 2 weeks - 84 months (mean $24 \pm 11.5$ months) (Table 2).

The duration of symptoms ranged from 1 week - 40 weeks (mean of $11.3 \pm 9.5$ ) Table 3.

Similar oral signs and symptoms were noted in both herbal dentifrices identified in this study. These include burning mouth and peppery sensation, mucosal erythema, lichenoid reaction, xerostomia, loss of taste sensation, angio-oedema as well as oral and peri-oral pigmentation. Burning mouth/peppery in the study was used to describe a fiery sensation in the oral cavity associated with an inability to tolerate spicy foods. Soreness of the oral mucosa in this study was described as the sensation of the presence of oral ulcers without any visible ulceration.

The most frequently observed finding was peppery/ burning mouth sensation. Table 4 shows signs, symptoms and frequency of occurrence of the mucosal responses in the study population.

All the patients in this study had more than one mucosal reaction to the identified herbal dentifrices.

In many patients, resolution of symptoms was progressive within 2 weeks of withdrawal of the herbal toothpaste and its replacement with a conventional fluoride toothpaste. Most of the patients however required further treatment.

A statistically significant association was found between the use of the identified herbal dentifrices and the following mucosal signs and symptoms, namely burning/ peppery sensation ( $\mathrm{p}$ value $=0.000$ and confidence interval (CI) $6.32,19.53)$, loss of taste sensation ( $\mathrm{p}$ value $=$ $0.021, \mathrm{CI}=4.53,22.73$ ), soreness $(\mathrm{p}$ value $=0.047, \mathrm{CI}=$ $4.55,32.87)$, erythema ( $\mathrm{p}$ value $=0.044, \mathrm{CI}=4.55,32.87$ ) and lichenoid straie ( $\mathrm{p}$ value $=0.000, \mathrm{CI}=0.044,0.33$ )

No statistically significant association was found between the use of herbal toothpaste and mucosal signs and symptoms of xerostomia ( $\mathrm{p}$ value $=0.067, \mathrm{CI}=$ undefined), angular cheilitis ( $\mathrm{p}$ value $=0.397, \mathrm{CI}=0.46,4.26$ )

Table 1. Age and gender distribution of patients.

\begin{tabular}{ccccc}
\hline Age grp/years & Male & Female & Total & $\%$ \\
\hline $10-20$ & - & 2 & 2 & 4.40 \\
$21-30$ & 2 & 4 & 6 & 13.30 \\
$31-40$ & - & 10 & 10 & 22.20 \\
$41-50$ & 5 & 10 & 15 & 33.30 \\
$51-60$ & - & 6 & 6 & 13.30 \\
$61-70$ & 2 & 1 & 3 & 6.75 \\
$71-80$ & - & 3 & 3 & 6.75 \\
Total & 9 & 36 & 45 & 100 \\
\hline
\end{tabular}

Table 2. Duration of usage of herbal toothpastes A and B.

\begin{tabular}{ccc}
\hline Duration of use (in months) & Number of patients & $\%$ \\
\hline $0-5$ & 10 & 22.2 \\
$6-10$ & 6 & 13.3 \\
$11-20$ & 6 & 13.3 \\
$21-30$ & 12 & 26.8 \\
$31-40$ & 3 & 6.7 \\
$41-50$ & 4 & 8.9 \\
$51-60$ & 2 & 4.4 \\
$61-70$ & 1 & 2.2 \\
$71-80$ & 0 & 0 \\
$81-90$ & 1 & 2.2 \\
\hline
\end{tabular}

Table 3. Duration of signs and symptoms prior to consultation.

\begin{tabular}{ccc}
\hline Duration (in weeks) & Number of patients & $\%$ \\
\hline $0-10$ & 23 & 51.1 \\
$11-20$ & 12 & 26.7 \\
$21-30$ & 4 & 8.9 \\
$31-40$ & 6 & 13.3 \\
\hline
\end{tabular}

Table 4. Distribution of symptoms observed in study group.

\begin{tabular}{|c|c|c|c|}
\hline $\mathrm{S} / \mathrm{N}$ & Symptoms & Frequency & $\%$ \\
\hline 1 & Peppery/burning sensation of the mouth & 33 & 21.7 \\
\hline 2 & Hyper pigmentation of the lips & 25 & 16.1 \\
\hline 3 & Loss of taste sensation/dysguesia & 20 & 13.1 \\
\hline 4 & Soreness of the oral mucosa & 17 & 11.1 \\
\hline 5 & $\begin{array}{l}\text { Erythema of the tongue, buccal mucosa, } \\
\text { palate }\end{array}$ & 12 & 7.8 \\
\hline 6 & Dryness of the oral mucosa/xerostomia & 11 & 7.2 \\
\hline 7 & Lichenoid-like striae & 14 & 9.2 \\
\hline 8 & Angular cheilitis & 7 & 4.6 \\
\hline 9 & Mucosal itching & 4 & 2.6 \\
\hline 10 & Oral ulcers & 5 & 3.3 \\
\hline 11 & Angioedema of the lips & 2 & 1.3 \\
\hline \multirow[t]{2}{*}{12} & Numbness of the oral mucosa & 3 & 2.0 \\
\hline & Total & ${ }^{*} 153$ & 100 \\
\hline
\end{tabular}

*Multiple symptoms in patients. 
mucosal itching $(\mathrm{p}$ value $=0.587, \mathrm{CI}=$ undefined $)$, angiooedema ( $\mathrm{p}$ value $=0.76, \mathrm{CI}=$ undefined $)$ and numbness ( $\mathrm{p}$ value $=0.644, \mathrm{CI}=$ undefined $)$.

All respondents indicated that the choice of the particular herbal toothpaste was not based on recommendation by a dentist or other oral health care professional. Figures 1-4 show clinical photographs of lesions seen.

Figure 1 shows circumoral pigmentation;

Figure 2 shows labial and intra-oral pigmentation;

Figure 3 shows erythema of the vermillion border and oral mucosa;

Figure 4 shows gingival erythema.

\section{DISCUSSION}

Observation from this study suggests that regular use of some herbal dentifrices may result in adverse oral and peri-oral mucosal responses. The study population cuts across all age groups and patients exhibited varying duration of exposure to the implicated herbal dentifrices. There was also variation in duration of symptoms prior to presentation for oral consultation .The varying mucosal responses to the herbal dentifrice and the variation in time frame for such responses may suggest individual reactions to the use of herbal dentifrices. The factors responsible for this variation may need to be identified and considered during clinical trials of non-conventional toothpastes.

The role of the interplay of hormonal factors in female patients may be inconclusive in spite of the female preponderance in this preliminary study. This may need to

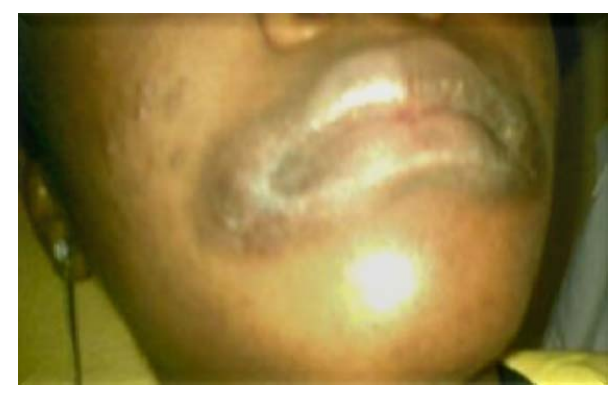

Figure 1. Circumoral hyperpigmentation.

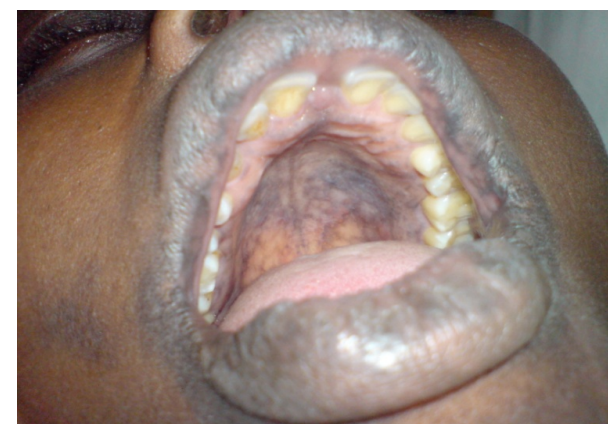

Figure 2. Labial and intraoral hyperpigmentation.

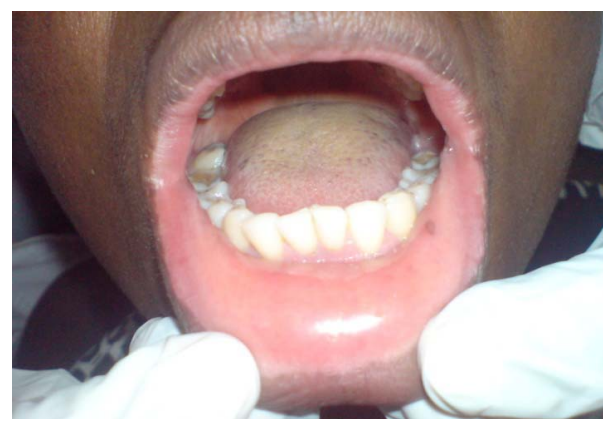

Figure 3. Erythema of the oral mucosa.

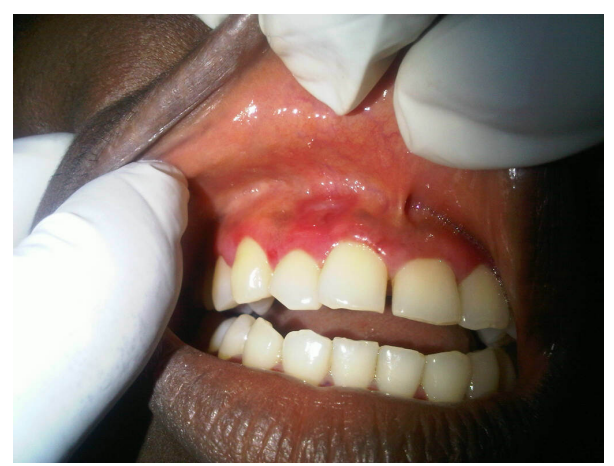

Figure 4. Gingival erythema.

be clarified in subsequent studies.

Statistically significant association seen between the use of the herbal dentifrices and mucosal responses of burning mouth/peppery sensation, loss of taste sensation, soreness and erythema suggests that these symptoms may not always be attributed to vitamin deficiencies or anaemias in patients presenting in the oral diagnosis clinic. Lichenoid straie may represent a form of allergic reaction similar to lichenoid drug reaction Further studies may also need to ascertain role of atopy or allergic reactions in responses to use of herbal dentifrice.

No significant association was seen in xerostomia, hyper pigmentation, angular cheilitis, mucosal itching angio-oedema and numbness.

All respondents in this study indicated that their choice of herbal dentifrice was not based on professional recommendation. This may not be unconnected with reports that consumer acceptance of herbal medicines is partly based on the incorrect assumption that "natural" equals safe [22]. The ready availability of herbal dentifrices in the market coupled with the lack of restrictions to their purchase and use may also contribute to the consumers' procurement without professional consultation. As the popularity of natural medicines and dentifrices continues to rise, dental professionals are said to be in a position to provide information to patients regarding their efficacy and safety. The lack of professional consensus on the subject is said to have made this difficult [23]. 
Most literature on herbal dentifrices focus on their efficacy over conventional toothpastes rather than on mucosal responses to their use. In a study spanning over six months conducted in 1998 at the College of Dentistry, New York University, Estafan et al. reported that herbal toothpaste and gum therapy were superior to conventional toothpaste in the reduction of plaque and stains [24]. These findings were at variance with a previous study conducted in Northern Ireland 1995 by Mullally et al. who concluded that the herbal based toothpaste was as effective as conventionally formulated dentifrice in the control of plaque and gingivitis. This group of researchers carried out a 6-week study to assess the efficacy of a herbal based toothpaste on the control of plaque and gingivitis [25]. In a related study in India, George and his team also compared the efficacy of a herbal based toothpaste over a conventional brand in the control of plaque and gingivitis. Their conclusion corroborated those of Mullaly et al. that neither had an advantage over the other in the control of plaque and gingivitis [26].

A randomized, double blind controlled trial conducted in the School of Dentistry Ibirapuera, Brazil by Ozaki et al. also reported that there was no significant difference in reduction of gingivitis in those using a herbal dentifrice against those using a non-herbal dentifrice [27].

These studies were largely short term studies conducted mainly to assess the superiority of one over the other with respect to the patient's periodontal condition. No record was made on the oral mucosal effects in the study group following use of the herbal dentifrice.

In 2007, Anil reported three cases of plasma cell gingivitis which he considered a hypersensitivity reaction following regular use of herbal dentifrices among herbal toothpaste users. He described plasma cell gingivitis (PCG) as a rare benign condition of the gingiva characterized by sharply demarcated erythematous and edematous gingivitis often extending to the mucogingival junction [28]. Gingival lesions observed in this study presented as erythematous areas devoid of edema (Figure 4). All the lesions seen in this study following the use of herbal toothpaste were described clinically, no histopathological diagnosis was carried out.

The role of herbal dentifrices in maintaining optimum oral health is not very clear. Issues that need clarification also include the frequency of use and whether such dentifrices are for daily, prophylactic or therapeutic use. Other unresolved issues include whether the herbal dentifrices are to be used interchangeably or synergistically with the conventional fluoride toothpaste. Areas that could be explored include the incorporation of the herbal dentifrices into prophylactic pastes used for patients with active periodontal conditions.

Claims made by manufacturers and marketers of these products need to be scientifically verified over a sufficient period of time. The residual effects observed in some of the patients following withdrawal of the herbal dentifrices also pose a source of concern.

The role of regulating bodies such as National Association for Food, Drugs and Administrative Control (NAFDAC) and the Nigerian Dental Association (NDA) in approving these products for use is not clearly defined and this needs to be addressed.

\section{CONCLUSIONS}

The regular use of the herbal dentifrices identified in this study can result in adverse oral signs and symptoms affecting taste, nutrition, aesthetics and general oral physiology in some consumers. These findings would suggest that further long term clinical trials need to be conducted on herbal dentifrices available to consumers to identify the noxious agents causing these adverse reactions. There is a need to standardize and regulate the use of herbal dentifrices.

Dental practitioners should be aware that the oral and peri-oral effects of daily use of some herbal dentifrices could contribute to patient clinic attendance and may lead to increase morbidity in these patients.

\section{REFERENCES}

[1] Jha, V. and Rathi, M. (2008) Natural medicines causing acute kidney injury. Seminars in Nephrology, 28, 416-428. doi:10.1016/j.semnephrol.2008.04.010

[2] Luyckx, V.A. and Naicker, S. (2008) Acute kidney injury associated with the use of traditional medicines. Nature Clinical Practice Nephrology, 4, 664-671. doi: $10.1038 /$ ncpneph0970

[3] JHA, V. (2010) Herbal medicines and chronic kidney disease. Nephrology, 15, 10-17. doi:10.1111/j.1440-1797.2010.01305.x

[4] Brandt, H.D. and Muller, G.J. (1995) Traditional medicines and acute poisoning. Continuing Medical Education, 13, 1053-1060.

[5] Hutchings, A. and Terblanche, S.E. (1989) Observations on the use of some known and suspected toxic lilliflorae in Xhosa and Zulu medicines. South African Medical Journal, 75, 62-69.

[6] Steenkamp, V. (2003) Traditional herbal remedies used by South African women for gynaecological complaints. Journal of Ethnopharmacology, 86, 97-108. doi:10.1016/S0378-8741(03)00053-9

[7] Gogtay, N.J., Bhatt, H.A., Dalvi, S.S. and Kshirsagar, N.A. (2002) The use and safety of non-allopathic Indian medicines. Drug Safety, 25, 1005-1009. doi:10.2165/00002018-200225140-00003

[8] Association, B.M. (1993) Complementary Medicine. New Approaches to Good Practice. 1st Edition, Oxford University Press, Oxford. 
[9] Eisenberg, D., Kessler, R.C., Foster, C., Norlock, F.E., Calkins, D.R. and Delbanco, T.L. (1993) Unconventional medicine in the United States: Prevalence, costs, and patterns of use. New England Journal of Medicine, 328, 246-252. doi:10.1056/NEJM199301283280406

[10] Skidmore-Roth, L. (2001) Mosby's handbook of herbs and natural supplements. 4th Edition, Mosby, St. Louis.

[11] Presser, A.M. (2000) Pharmacist's guide to medicinal herbs. 1st Edition, Smart Publications, Petaluma.

[12] Barrett, B., Kiefer, D. and Rabago, D. (1999) Assessing the risks and benefits of herbal medicine: An overview of scientific evidence. Alternative Therapies in Health and Medicine, 5, 40-49.

[13] Cohan, R.P. and Jacobsen, P.L. (2000) Herbal supplements: Considerations in dental practice. Journal of the California Dental Association, 28, 600-610.

[14] Gruenwald, J. (2000) PDR for herbal medicine. 2nd Edition, Medical Economics.

[15] Rees, A.M. (2001) Extent and usage of complementary and alternative medicine. In: Rees, A.M., Ed., The Complementary and Alternative Medicine Information Source Book, Oryx Press, Phoenix, 3.

[16] White, L.B. and Foster, S. (2000) The herbal drugstore: The best natural alternatives to over-the-counter and prescription medicines. Rodale, Inc., Emmaus.

[17] Sean, S.L., Zhang, W. and Li, Y. (2004) The antimicrobial potential of 14 natural herbal dentifrices: Results of an in vitro diffusion method study. Journal of the American Dental Association, 135, 1133-1141.

[18] Goldstern, B.H. and Epstein, J.B. (2000) Unconventional dentistry, part IV unconventional dental practices and products. Journal of the Canadian Dental Association, 66, 564-548.

[19] Moran, J., Addy, M. and Newcombe, R. (1991) Comparison of an herbal tooth-paste with a fluoride toothpaste on plaque and gingivitis. Clinical Preventive Dentistry, 13,
12-15.

[20] Thibault, C. (2001) Update on toothpastes. Probe, 35, 25-28.

[21] Li, Y. (1997) Toxicological considerations of tooth bleaching using peroxide-containing agents. Journal of the American Dental Association, 128, 31s-36s.

[22] Nutrition News Focus (1999) Everywhere you turn: Herbs. http://www.nutritionnewsfocus.com/

[23] Eisenberg, D.M., Davis, R.B., Ettner, S.L., Appel, S., Van Rowpay, M. and Kessler, R.C. (1998) Trends in alternative medicine use in the United States, 1990-1997: Results of a follow-up national survey. Journal of the American Medical Association, 280, 1569-1575. doi:10.1001/jama.280.18.1569

[24] Estafan, D., Gultz, J., Kaim, J.M., Khaghany, K. and Scherer, W. (1988) Clinical efficacy of a herbal toothpaste. Journal of Clinical Dentistry, 9, 31-33.

[25] Mullally, B.H., James, J.A., Coulter, W.A. and Linden, G.J. (1995) The efficacy of a herbal based toothpaste on the control of plaque and gingivitis. Journal of Clinical Periodontology, 22, 686-689. doi:10.1111/j.1600-051X.1995.tb00827.x

[26] George, J., Hedge, S., Rajesh, K.S. and Kumar, A. (2009) The efficacy of a herbal based toothpaste in the control of plaque and gingivitis: A clinico-biochemical study. Indian Journal of Dental Research, 20, 480-482.

[27] Ozaki, F., Pannuti, C.M., Imbronito, A.V., Pessotti, W., Saraiva, L., De Freitas, N.M., Ferrari, G. and Cabral, V.N. (2006) Efficacy of a herbal toothpaste on patients with established gingivitis-A randomized control trial, Brazilian Oral Research, 20, 172-177. doi:10.1590/S1806-83242006000200015

[28] Anil, S. (2007) Plasma cell gingivitis among herbal toothpaste users: A report of three cases. Journal of Contemporary Dental Practice, 8, 60-66. 